\title{
Renal resistive index is associated with acute kidney injury in COVID-19 patients treated in the intensive care unit
}

\author{
Mårten Renberg ${ }^{1,2^{*}}$ (D) Olof Jonmarker ${ }^{3}$, Naima Kilhamn ${ }^{1}$, Claire Rimes-Stigare ${ }^{1,2}$, Max Bell ${ }^{1,2}$ \\ and Daniel Hertzberg ${ }^{1,2}$
}

\begin{abstract}
Background: Renal resistive index (RRI) is a promising tool for the assessment of acute kidney injury (AKI) in critically ill patients in general, but its role and association to AKI among patients with Coronavirus disease 2019 (COVID-19) is not known.

Objective: The aim of this study was to describe the pattern of RRI in relation to AKI in patients with COVID-19 treated in the intensive care unit.

Methods: In this observational cohort study, RRI was measured in COVID-19 patients in six intensive care units at two sites of a Swedish University Hospital. AKI was defined by the creatinine criteria in the Kidney Disease Improving Global Outcomes classification. We investigated the association between RRI and AKI diagnosis, different AKI stages and urine output.
\end{abstract}

Results: RRI was measured in 51 patients, of which 23 patients (45\%) had AKI at the time of measurement. Median RRI in patients with AKI was 0.80 (IQR 0.71-0.85) compared to 0.72 (IQR 0.67-0.78) in patients without AKI $(p=0.004$ ). Compared to patients without AKI, RRI was higher in patients with AKI stage 3 (median 0.83, IQR 0.71-0.85, $p=0.006$ ) but not in patients with AKI stage 1 (median 0.76, IQR 0.71-0.83, $p=0.347$ ) or AKI stage 2 (median 0.79, $\mathrm{min} / \mathrm{max}$ $0.79 / 0.80, n=2, p=0.134$ ). RRI was higher in patients with an ongoing AKI episode compared to patients who never developed AKI (median 0.72, IQR 0.69-0.78, $p=0.015$ ) or patients who developed AKI but had recovered at the time of measurement (median 0.68, IQR 0.67-0.81, $p=0.021$ ). Oliguric patients had higher RRI (median 0.84, IQR 0.83-0.85) compared to non-oliguric patients (median 0.74 , IQR 0.69-0.81) ( $p=0.009$ ). After multivariable adjustment, RRI was independently associated with AKI (OR for 0.01 increments of RRI 1.22, 95\% Cl 1.07-1.41).

Conclusions: Critically ill COVID-19 patients with AKI have higher RRI compared to those without AKI, and elevated RRI may have a role in identifying severe and oliguric AKI at the bedside in these patients.

Keywords: Renal resistive index, Point-of-care ultrasound, Ultrasonography, Renal Doppler, Acute kidney injury, COVID-19

\footnotetext{
*Correspondence: marten.renberg@sll.se

${ }^{1}$ Department of Perioperative Medicine and Intensive Care, Karolinska

University Hospital, Solna, 17176 Stockholm, Sweden

Full list of author information is available at the end of the article
}

\begin{abstract}
Background
The Coronavirus disease 2019 (COVID-19) pandemic is causing great suffering and is placing strain on health care systems worldwide. Acute kidney injury (AKI) is a common complication in critically ill patients with COVID-19. Initial studies have reported an incidence from 20 to almost $90 \%$ among patients admitted to the
\end{abstract}

Springer Open

(c) The Author(s) 2021. This article is licensed under a Creative Commons Attribution 4.0 International License, which permits use, sharing, adaptation, distribution and reproduction in any medium or format, as long as you give appropriate credit to the original author(s) and the source, provide a link to the Creative Commons licence, and indicate if changes were made. The images or other third party material in this article are included in the article's Creative Commons licence, unless indicated otherwise in a credit line to the material. If material is not included in the article's Creative Commons licence and your intended use is not permitted by statutory regulation or exceeds the permitted use, you will need to obtain permission directly from the copyright holder. To view a copy of this licence, visit http://creativeco mmons.org/licenses/by/4.0/. 
intensive care unit (ICU) or in need of mechanical ventilation [1-4], of which up to one-third have been treated with renal replacement therapy (RRT) [5, 6]. COVID-19 patients who develop AKI may have a 13-fold increased risk of death compared to those who do not develop AKI $[4,7,8]$.

Renal resistive index (RRI) is an ultrasonographic Doppler measurement of flow velocities in intraparenchymal renal arteries. Normal values are around $0.60[9,10]$ with 0.70 considered the upper normal threshold in adults [11]. Elevated RRI has shown promise in early detection and prognostication of AKI in mixed ICU populations [12-16], and the method seems feasible within the scope of point-of-care ultrasonography (POCUS) [17].

As thromboembolism and renal microangiopathy have gained interest as possible mechanisms giving rise to AKI in COVID-19 [18, 19], RRI may show to be an especially helpful tool to guide diagnosis and treatment of AKI in these patients. In a recent case-control study, reduced renal perfusion and substantially elevated RRI were described in ten COVID-19 patients with severe AKI [20]. However, RRI has not been described in larger populations of COVID-19 patients and its role in these patients remains unclear. The aim of this study was to describe the pattern of RRI in relation to AKI in patients with COVID-19 treated in the ICU. We specifically investigated if there was an association between RRI and AKI diagnosis, different AKI stages and urine output.

\section{Methods}

\section{Study population}

This was an observational cohort study conducted in six ICUs designated for COVID-19 patients (COVIDICUs) at the Karolinska University Hospital, Stockholm, Sweden. Four ICUs were at one of two sites, and two at the other site. On specific dates, patients in each COVID-ICU were screened for participation. Inclusion criteria were infection with Severe Acute Respiratory Syndrome Coronavirus 2 (SARS-CoV-2) detected by a positive reverse transcriptase-polymerase chain reaction taken from upper or lower airways, admission to a COVID-ICU, and age $\geq 18$ years. Exclusion criteria were end-stage renal disease (ESRD) before ICU admission, palliative phase of intensive care, ongoing irregular cardiac rhythm or treatment with extracorporeal membrane oxygenation (ECMO).

The study complied with the Declaration of Helsinki and was approved by the Swedish Ethical Review Authority. Requirement for signed informed consent was waived. A printed information sheet was sent to each patient or next of kin with the opportunity to retrospectively withdraw participation.

\section{Definitions}

AKI was defined according to the Kidney Disease Improving Global Outcomes (KDIGO) classification as an increase in serum creatinine concentration $(\mathrm{sCr})$ and categorized into three stages [21]. The highest $\mathrm{sCr}$ from ICU admission to the day of RRI measurement was compared to baseline $\mathrm{sCr}$. Baseline $\mathrm{sCr}$ was defined as the last known value measured in a disease-free phase before admission. When no previous $\mathrm{sCr}$ value existed, hospital admission $\mathrm{sCr}$ was used. The AKI stages were defined as the following: stage $1, \geq 1.5$ - to 1.9 -fold increase or an absolute increase $\geq 26 \mu \mathrm{mol} / \mathrm{l}$; stage $2, \geq 2.0$ - to 2.9 fold increase; stage 3, $\geq 3.0$-fold increase or an absolute increase $>354 \mu \mathrm{mol} / \mathrm{l}$ or initiation of RRT. The KDIGO urine output criteria were not used since hourly urine output was not always registered in the medical records. If the $\mathrm{sCr}$ elevation occurred more than 7 days before the RRI measurement and its value had returned to $<1.5$ fold or $<26 \mu \mathrm{mol} / \mathrm{l}$ higher than from baseline, the patient was evaluated as having recovered from an AKI episode and was classified into the no AKI group. Oliguria at the time of RRI measurement was defined as urine output $<0.5 \mathrm{ml} / \mathrm{kg}$ ideal body weight/hour for $24 \mathrm{~h}$ regardless of diuretic drug administration [22]. Ideal body weight was calculated using the gender-specific Acute Respiratory Distress Syndrome Network formula [23]. Chronic kidney disease (CKD) was defined as estimated glomerular filtration rate $(e G F R)<60 \mathrm{~mL} / \mathrm{min} / 1.73 \mathrm{~m}^{2}$, ESRD was defined as eGFR $<15 \mathrm{~mL} / \mathrm{min} / 1.73 \mathrm{~m}^{2}$, and eGFR was calculated using the Chronic Kidney Disease Epidemiology Collaboration (CKD-EPI) equation [24]. For this, baseline $\mathrm{sCr}$ was used when classifying patients as having CKD or ESRD, and a combination of $\mathrm{sCr}$ and cystatin C was used when calculating eGFR at the time of RRI measurement. Comorbidities were considered present if documented in the patient's medical record or if the patient was prescribed medication for the current state. The cardiovascular disease group included patients with cardiac failure, atrial arrhythmia, prior myocardial infarction or prior cardiac surgery.

\section{RRI measurements}

All RRI measurements were performed by one of two operators (MR and OJ). Both operators had more than one year's clinical experience of the RRI method. For each site a designated ultrasound device with a curvilinear probe of $1.0-6.0 \mathrm{MHz}$ was used (GE Vivid S70N, US and GE Logiq E10, US at the two sites, respectively). The patients were examined in their ICU bed in supine or prone position depending on their respiratory requirements. Both kidneys were examined, and measurements were made on both or the most accessible side since the 
difference in RRI values between the right and left kidney has been shown to be negligible both in healthy and critically ill patients $[9,12,17]$. After obtaining a complete view of the kidney, color-Doppler was applied to visualize the global organization of intrarenal blood vessels. Pulse waved Doppler at the smallest possible width between 2 and $5 \mathrm{~mm}$ was used to measure flow velocities in an interlobular or arcuate artery in the upper, middle and lower kidney pole. The Doppler gain was set to obtain a clear outline of flow waves with minimal background noise. The pulse waved Doppler spectrum was considered optimal when at least three consecutive similar-looking waveforms for each pole were visualized. RRI was calculated for each pole as [(peak systolic velocityend-diastolic velocity)/peak systolic velocity]. From the pole RRI values, a mean RRI was computed.

\section{Data collection}

The following clinical data were collected for each patient at the time of RRI measurement: hemodynamic parameters, vasopressor requirements, sedatives dose and ventilator settings if mechanically ventilated. Severity of illness was graded on the day of measurement using the Sequential Organ Failure Assessment (SOFA) (originally the Sepsis-related Organ Failure Assessment) score [25]. Information on comorbidities, regular and current medication and laboratory data were collected from medical records.

\section{Statistical analysis}

Patient characteristics and variables are presented using frequencies and percentages for categorical data, and medians with interquartile range (IQR) and minimum/ maximum $(\mathrm{min} / \mathrm{max})$ values for continuous data. Clinical characteristics of patients with or without AKI were compared using Fisher's exact test for dichotomous variables and Wilcoxon rank-sum test for continuous variables. Median RRI between different groups were compared using the Wilcoxon rank-sum test. To elucidate potential confounding of the association between RRI and AKI, a multivariable logistic regression model was performed including RRI as a continuous and AKI as a dichotomous variable. Variables in our dataset that were associated with AKI with a $p$-value $<0.2$ in bivariate logistic regression were selected for a manual forward selection procedure. Variables with the strongest association with AKI were included first, and variables that no longer were associated with AKI ( $p$-value $>0.2$ ) during forward selection were excluded. Remaining variables constituted the final model. Odds ratios (OR) and $95 \%$ confidence intervals (CI) were calculated. Goodness-of-fit of the model was assessed using the Hosmer-Lemeshow test. For all analyses a $p$-value $<0.05$ was considered significant. The following variables had missing data: hospital admission $\mathrm{sCr}(n=7[14 \%])$ and urine output at the day of RRI measurement $(n=2[4 \%])$. Missing data on height $(n=1$ [2\%]) were substituted with the median value according to sex. Statistical analyses were performed using Stata version 15.1 (StataCorp, College Station, US).

\section{Results}

Between April 15 and May 15 in 2020, the six COVIDICUs were screened on specific dates for each ICU when at least one of the operators was available and able to perform measurements. Out of 71 screened patients, 20 were excluded, and a total of 51 patients were analyzed (Fig. 1).

Patient characteristics of the study population are presented in Table 1. Median age was 63 (IQR 57-67, min/ $\max 29 / 74)$ and $88 \%$ were male. At the time of RRI measurement 23 patients (45\%) had AKI (stage 1, $n=4(8 \%)$; stage $2, n=2(4 \%)$; stage $3, n=17(33 \%)$ with $n=13(25 \%)$ treated with continuous RRT [CRRT]). Among the 28 patients (55\%) who did not have AKI, 11 patients (22\%) previously during the ICU course had an AKI episode but had recovered (recovered from stage 1, $n=7$ (14\%); from stage $2, n=2$ (4\%); from stage $3, n=2[4 \%]$ ) and 17 patients (33\%) never had AKI. Compared to patients without AKI, the AKI patients had a higher body mass index (BMI) and a lower incidence of cardiovascular disease. At the time of RRI measurement, AKI patients had a higher SOFA score, a higher incidence of mechanical ventilation and vasopressor use, lower eGFR and were more often oliguric compared to patients without AKI.

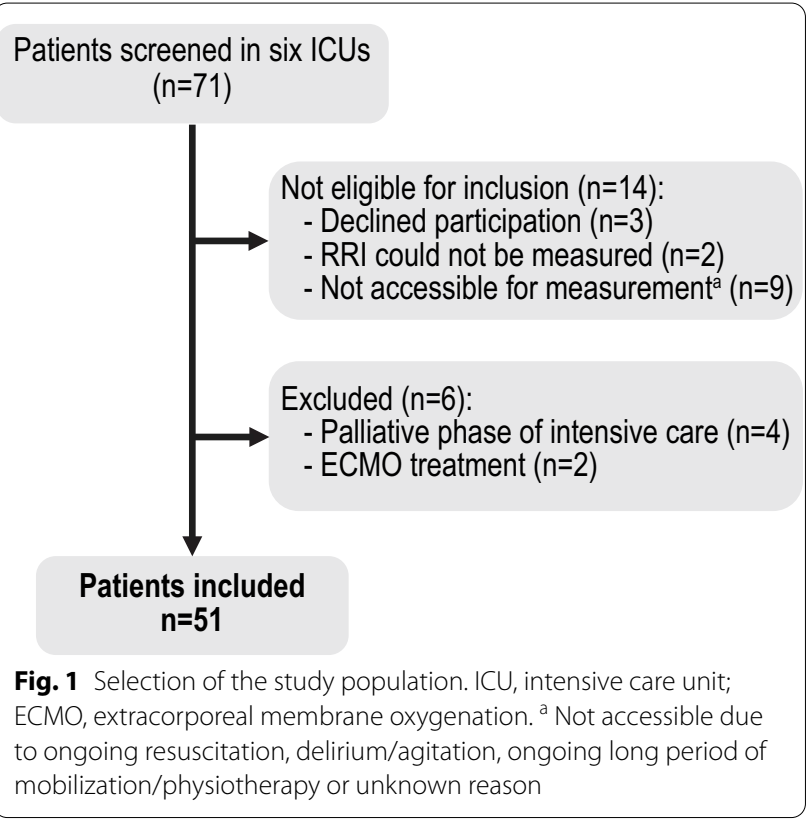


Table 1 Patient characteristics of all patients and those with and without AKI

\begin{tabular}{|c|c|c|c|c|}
\hline & All patients $(n=51)$ & No AKI $(n=28)$ & AKI $(n=23)$ & $\begin{array}{l}p \text {-value } \\
\text { no AKI vs } \\
\text { AKI }\end{array}$ \\
\hline Age, median (IQR) & $63(57-67)$ & $63(58-68)$ & $64(53-65)$ & 0.48 \\
\hline Sex, $n(\%)$ & & & & 0.027 \\
\hline Male & $45(88)$ & $22(79)$ & $23(100)$ & \\
\hline Female & $6(12)$ & $6(21)$ & $0(0)$ & \\
\hline BMI, median (IQR) & $28.7(25.2-31.2)$ & $26.8(24.6-29.9)$ & $30.9(27.0-34.7)$ & 0.012 \\
\hline \multicolumn{5}{|l|}{ Risk factors for AKI, $n(\%)$} \\
\hline Hypertension & $29(57)$ & $15(54)$ & $14(61)$ & 0.78 \\
\hline Diabetes & $10(20)$ & $5(18)$ & $5(22)$ & 0.74 \\
\hline Chronic lung disease & $11(22)$ & $7(25)$ & $4(17)$ & 0.73 \\
\hline Cardiovascular disease & $6(12)$ & $6(21)$ & $0(0)$ & 0.027 \\
\hline Chronic kidney disease $\mathrm{e}^{\mathrm{a}, \mathrm{c}}$ & $6(12)$ & $1(4)$ & $5(22)$ & 0.079 \\
\hline End-stage renal disease $e^{b, c}$ & $0(0)$ & & & \\
\hline No risk factor ${ }^{d}$ & $15(29)$ & $7(25)$ & $8(35)$ & 0.54 \\
\hline \multicolumn{5}{|l|}{ Data at RRI measurement } \\
\hline ICU day, median (IQR) & $18(6-29)$ & $16(6-26)$ & $19(10-31)$ & 0.19 \\
\hline SOFA score, median (IQR) & $5(4-8)$ & $4(3-7)$ & $7(5-10)$ & 0.003 \\
\hline Mechanical ventilation, $n(\%)$ & $38(75)$ & $17(61)$ & $21(91)$ & 0.022 \\
\hline Prone position, $n(\%)$ & $9(18)$ & $5(18)$ & $4(17)$ & 1.00 \\
\hline Vasopressors, n (\%) & $26(51)$ & $10(36)$ & $16(70)$ & 0.025 \\
\hline $\mathrm{eGFR}^{\mathrm{C}}$, median (IQR) & $58(41-75)$ & $70(52-80)$ & $26(13-41)$ & $<0.001$ \\
\hline Oliguria $^{e}, n(\%)$ & $5(24)$ & $0(0)$ & $5(24)$ & 0.011 \\
\hline \multicolumn{5}{|l|}{ RRT, $n(\%)$} \\
\hline Continuous RRT & $13(25)$ & $0(0)$ & $13(57)$ & $<0.001$ \\
\hline Intermittent HD & $0(0)$ & & & \\
\hline \multicolumn{5}{|l|}{ Treatment in ICU,$n(\%)$} \\
\hline Mechanical ventilation & $49(96)$ & $26(93)$ & $23(100)$ & 0.49 \\
\hline Vasopressors & $49(96)$ & $26(93)$ & $23(100)$ & 0.49 \\
\hline \multicolumn{5}{|l|}{ RRT } \\
\hline Continuous RRT & $13(25)$ & $0(0)$ & $13(57)$ & $<0.001$ \\
\hline Intermittent HD & $1(2)$ & $0(0)$ & $1(4)$ & 0.45 \\
\hline Diuretics & $48(94)$ & $25(89)$ & $23(100)$ & 0.24 \\
\hline \multicolumn{5}{|l|}{ Anti-inflammatory drugs } \\
\hline Corticosteroids & $37(73)$ & $21(75)$ & $16(70)$ & 0.76 \\
\hline Tocilizumab & $3(6)$ & $3(11)$ & $0(0)$ & 0.24 \\
\hline \multicolumn{5}{|l|}{ Antiviral drugs } \\
\hline Chloroquine phosphate & $1(2)$ & $0(0)$ & $1(4)$ & 0.45 \\
\hline Remdesivir & $2(4)$ & $2(7)$ & $0(0)$ & 0.49 \\
\hline \multicolumn{5}{|l|}{ Anticoagulation drugs } \\
\hline LMWH & $51(100)$ & $28(100)$ & $23(100)$ & \\
\hline Antiplatelets & $33(65)$ & $21(75)$ & $12(52)$ & 0.14 \\
\hline Episode of thrombolysis & $4(8)$ & $1(4)$ & $3(13)$ & 0.32 \\
\hline
\end{tabular}

AKI acute kidney injury, BMI body mass index $\left(\mathrm{kg} / \mathrm{m}^{2}\right)$, RRI renal resistive index, ICU intensive care unit, SOFA score Sequential Organ Failure Assessment score, eGFR estimated glomerular filtration rate $\left(\mathrm{ml} / \mathrm{min} / 1.73 \mathrm{~m}^{2}\right), R R T$ renal replacement therapy, $H D$ hemodialysis, $L M W H$ low-molecular-weight heparin

${ }^{a}$ Chronic kidney disease was defined as eGFR before ICU admission $<60 \mathrm{ml} / \mathrm{min} / 1.73 \mathrm{~m}^{2}$

${ }^{b}$ End-stage renal disease was defined as eGFR before $\mathrm{ICU}$ admission $<15 \mathrm{ml} / \mathrm{min} / 1.73 \mathrm{~m}^{2}$

c eGFR was calculated using the CKD-EPI equation using serum creatinine for classification of chronic kidney disease and end-stage renal disease, and a combination of serum creatinine and cystatin $\mathrm{C}$ at the time of RRI measurement

d Patients without history of smoking, chronic diagnoses or regular medications at hospital admission

e Oliguria was defined as urine output $<0.5 \mathrm{ml} / \mathrm{kg}$ ideal body weight/hour for $24 \mathrm{~h}$

f Treatment from ICU admission to RRI measurement 

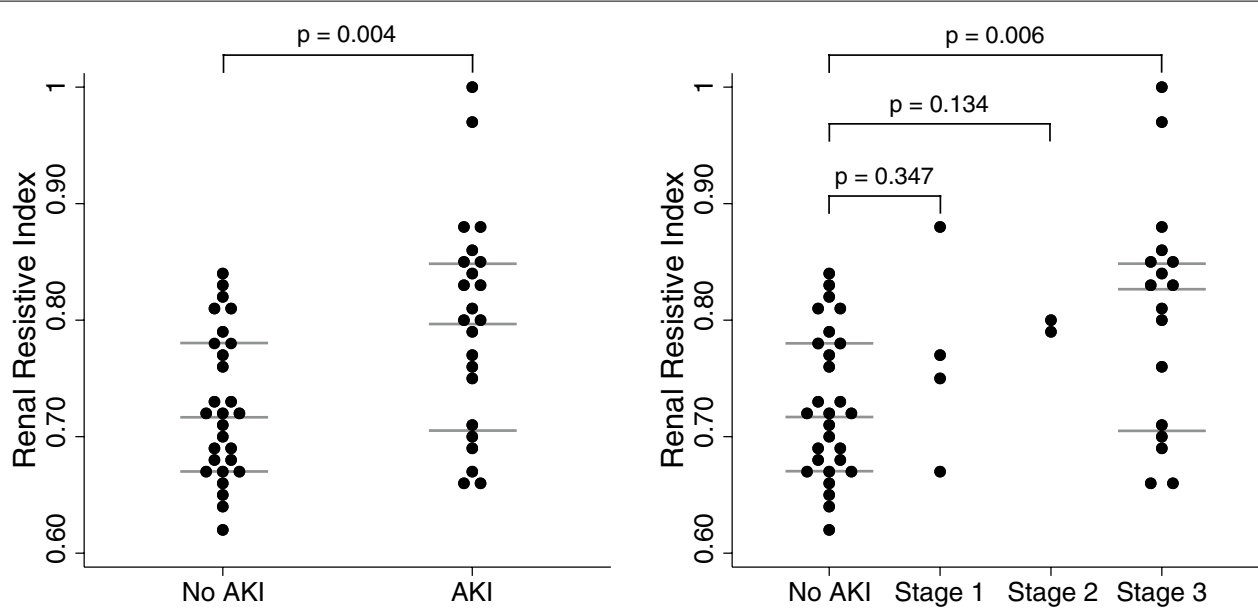

Fig. 2 Dot plot illustrating the association between renal resistive index and acute kidney injury (AKI) in patients with or without AKI (left) and patients with different stages of AKI (right). Each dot represents a patient. The horizontal lines represent the median, upper and lower quartiles

RRI was measured most often in the third week of the ICU and hospital course (median ICU day 18, IQR 6-29, $\mathrm{min} / \mathrm{max}$ 0/37; median hospital day 20, IQR 10-30, min/ $\max 2 / 37$ ) and 4 weeks from symptom debut of COVID19 (median 28, IQR 22-40, $\mathrm{min} / \mathrm{max} 7 / 72$ ). In 27 patients (53\%) RRI was calculated from measurements in the right kidney, in 12 patients $(23,5 \%)$ from measurements in the left kidney and in 12 patients (23,5\%) from measurements in both kidneys. Forty-two patients (82\%) were examined in supine and nine patients (18\%) in prone position.

\section{RRI in relation to $A K I$ and $A K I$ stage}

Median RRI in the study population was 0.76 (IQR 0.69$0.82, \mathrm{~min} / \mathrm{max} 0.62 / 1.0$ ). One patient had completely diminished end-diastolic blood flow resulting in an RRI of 1.0. Median RRI in patients with AKI was 0.80 (IQR 0.71$0.85, \mathrm{~min} / \max 0.66 / 1.0$ ) compared to 0.72 (IQR 0.67-0.78, $\mathrm{min} / \max 0.62 / 0.84)$ in patients without AKI $(p=0.004)$ (Fig. 2). There was no difference in RRI between AKI stage 1 (median 0.76, IQR 0.71-0.83, $\mathrm{min} / \max 0.67 / 0.88$ ) or AKI stage 2 (median $0.79, \min / \max 0.79 / 0.80, n=2$ ) compared to no AKI ( $p=0.347$ and 0.134 , respectively), but RRI was higher in patients with AKI stage 3 (median 0.83, IQR $0.71-0.85, \mathrm{~min} / \mathrm{max} 0.66 / 1.0)$ compared to patients without AKI ( $p=0.006)$ (Fig. 2).

\section{$\mathrm{RRI}$ in relation to non-AKI, recovered $\mathrm{AKI}$ and ongoing $\mathrm{AKI}$}

RRI did not differ within the no AKI group when comparing patients who never had AKI (median 0.72, IQR $0.69-0.78, \min / \max 0.62 / 0.83)$ to patients with recovered AKI (median 0.68, IQR 0.67-0.81, $\mathrm{min} / \mathrm{max}$ $0.65 / 0.84)(p=0.621)$, but RRI was higher in the AKI group compared to both these groups ( $p=0.015$ and 0.021, respectively) (Fig. 3).

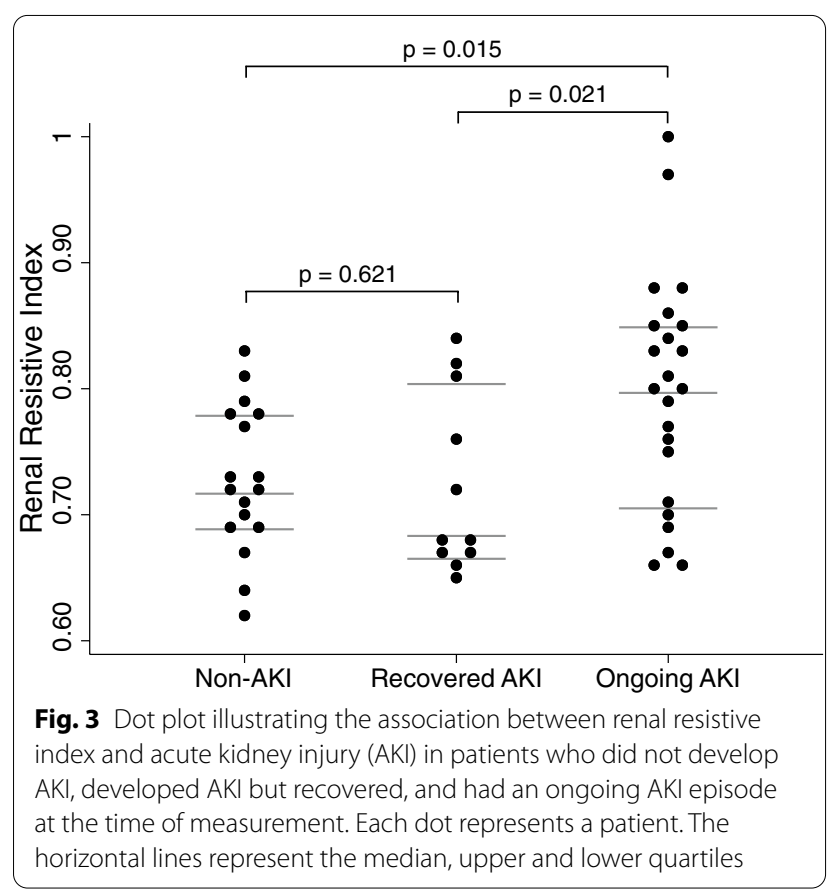

\section{$\mathrm{RRI}$ in relation to oliguria}

RRI was higher in oliguric patients (median 0.84, IQR 0.83-0.85, $\mathrm{min} / \max 0.80 / 0.97$ ) compared to non-oliguric patients (median 0.74, IQR 0.69-0.81, $\min / \max 0.62 / 1.0$ ) $(p=0.009)$ (Fig. 4).

\section{Multivariable analysis}

Bivariate and multivariable logistic regression analysis is presented in Table 2. Possible confounders eligible for inclusion in the multivariable model are all variables presented in Table 1 except those that could be influenced by 


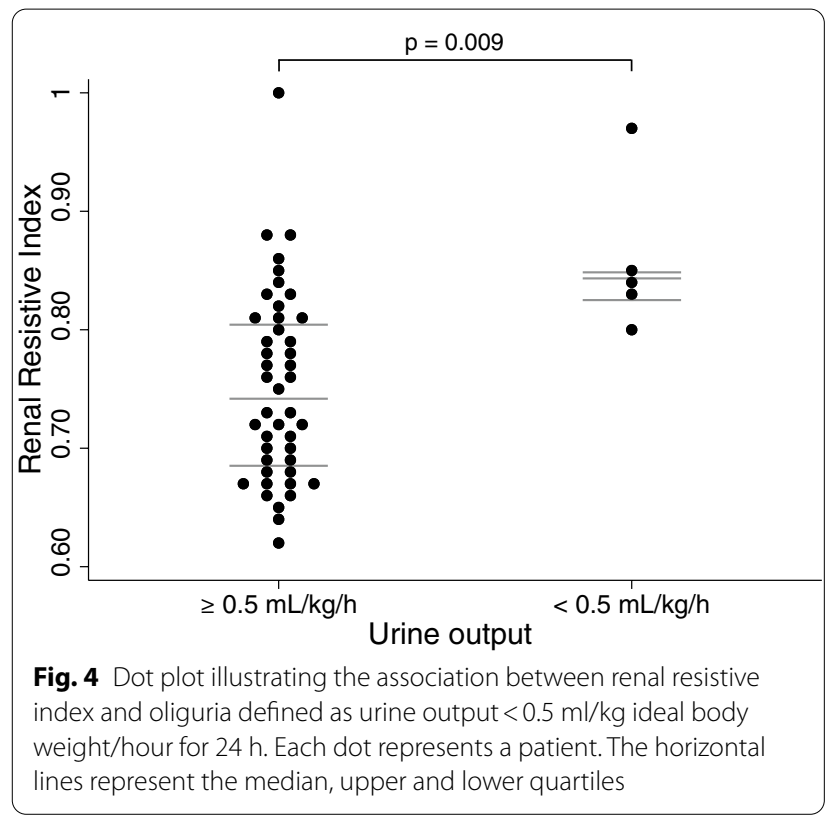

AKI and hence be part of a causal chain (ICU day, SOFA score, eGFR, oliguria, RRT, administration of diuretics). The following variables were omitted due to perfect prediction in the AKI groups (sex, cardiovascular disease, mechanical ventilation during ICU course, vasopressors during ICU course, tocilizumab, chloroquine phosphate, remdesivir, low-molecular-weight heparin). Variables included in the final model were RRI, BMI, CKD, vasopressors at measurement and administration of antiplatelet drugs. After multivariable adjustment, RRI was independently associated with AKI (OR for 0.01 increments of RRI 1.22, 95\% CI 1.07-1.41). Goodness-of-fit had $p=0.705$.

\section{Discussion}

This study presents novel findings of the pattern of RRI in critically ill patients with COVID-19. RRI was higher in patients with AKI compared to patients without AKI, and the difference was significant in patients with AKI stage 3 but not in patients with AKI stage 1 or 2 . RRI was higher in patients with an ongoing AKI episode compared to

Table 2 Bivariate and multivariable analysis showing the association with AKI

\begin{tabular}{|c|c|c|c|c|}
\hline & \multicolumn{2}{|c|}{ Bivariate analysis } & \multicolumn{2}{|c|}{ Multivariable analysis ${ }^{a}$} \\
\hline & OR $(95 \% \mathrm{Cl})$ & $p$-value & OR $(95 \% \mathrm{Cl})$ & $p$-value \\
\hline RRI (0.01 unit step) & $1.13(1.04-1.23)$ & 0.005 & $1.22^{b}(1.07-1.41)$ & 0.004 \\
\hline Age & $0.97(0.91-1.03)$ & 0.296 & & \\
\hline BMl & $1.11(0.99-1.23)$ & 0.067 & $1.23(1.02-1.48)$ & 0.031 \\
\hline \multicolumn{5}{|l|}{ Risk factors for AKI } \\
\hline Hypertension & $1.35(0.44-4.13)$ & 0.601 & & \\
\hline Diabetes & $1.28(0.32-5.10)$ & 0.729 & & \\
\hline Chronic lung disease & $0.63(0.16-2.50)$ & 0.513 & & \\
\hline Chronic kidney disease $^{c}$ & $7.50(0.81-70)$ & 0.076 & $175(3.72-8281)$ & 0.009 \\
\hline No risk factor ${ }^{d}$ & $1.60(0.48-5.37)$ & 0.447 & & \\
\hline \multicolumn{5}{|l|}{ Data at RRI measurement } \\
\hline Mechanical ventilation & $6.79(1.32-35)$ & 0.022 & f & \\
\hline Prone position & $0.97(0.23-4.12)$ & 0.965 & & \\
\hline Vasopressors & $4.11(1.27-13)$ & 0.019 & $27(2.68-268)$ & 0.005 \\
\hline \multicolumn{5}{|l|}{ Treatment in ICU } \\
\hline \multicolumn{5}{|l|}{ Anti-inflammatory drugs } \\
\hline Corticosteroids & $0.76(0.22-2.61)$ & 0.666 & & \\
\hline \multicolumn{5}{|l|}{ Anticoagulation drugs } \\
\hline Antiplatelets & $0.36(0.11-1.19)$ & 0.094 & $0.18(0.03-1.17)$ & 0.073 \\
\hline Episode of thrombolysis & $4.05(0.39-42)$ & 0.241 & & \\
\hline
\end{tabular}

$A K I$ acute kidney injury, $O R$ odds ratio, $C l$ confidence interval, $R R /$ renal resistive index, $B M I$ body mass index $\left(\mathrm{kg} / \mathrm{m}^{2}\right), I C U$ intensive care unit

a Goodness-of-fit $p=0.705$

b An increase of 0.01 in RRI increased the risk of having AKI at measurement by $22 \%$

c Chronic kidney disease was defined as eGFR before ICU admission $<60 \mathrm{ml} / \mathrm{min} / 1.73 \mathrm{~m}^{2}$

$d$ Patients without history of smoking, chronic diagnoses or regular medications at hospital admission

e Treatment from ICU admission to RRI measurement

f Variable excluded from multivariable logistic regression model during forward selection 
patients who had recovered from AKI earlier during the ICU course. Oliguric patients had higher RRI compared to non-oliguric patients. The association between RRI and AKI remained significant after adjustment for possible confounding.

Our results are in line with previous studies on mixed or septic ICU patients instead designed to investigate the role of RRI to predict and prognosticate AKI [12, 13, 16, 26, 27]. These studies have suggested RRI to be able to distinguish severe or persistent AKI from no or transient AKI, with optimal cut-off values for this discrimination varying from 0.69 to 0.80 . The median RRI of 0.80 in patients with AKI in our population must be considered high in comparison, but may partly be due to the large proportion of patients with AKI stage 3. This is in line with the results of a recent case-control study which presented higher RRI in ten COVID-19 patients with AKI stage 3 compared to ten patients with AKI from septic shock [20]. Notably, also patients without AKI in our study had higher RRI (median 0.72) compared to non-AKI patients in ICU populations without COVID-19 where reported values typically are lower than $0.65[12$, 14, 28]. It is not clear if elevated RRI in patients without AKI but infected with SARS-CoV-2 is specifically related to the infection itself, or if it reflects severity of illness as indicated by the long length of ICU stay as well as the high incidence of mechanical ventilation and vasopressor use in our population.

There is growing evidence of reduced renal microperfusion in patients with COVID-19-related AKI, both from contrast enhanced ultrasonographic measurements in patients with severe AKI [20] as well as from post-mortem findings of microvascular obstruction [29]. In addition, numerous studies have reported high rates of thrombotic complications in hospitalized COVID19 patients in general [30-32], and thrombi in the renal microcirculation has been mentioned as a possible mechanism contributing to AKI in these patients [2]. Even if several renal and extrarenal factors influence the final profile of the RRI flow wave and value [33], it is conceivable that renal microcirculatory disturbances further contributed to the generally high RRI values observed in our population.

Previous studies on critically ill patients without COVID-19 have in general focused on prediction of AKI from RRI measurements performed within the first day of ICU admission [12, 14-16, 26]. However, the ability of early RRI measurements to predict short-term AKI reversibility within 3 days recently has been challenged [34, 35]. Our finding of higher RRI in COVID19 patients with an ongoing AKI episode compared to patients who had recovered from an AKI episode earlier during the ICU course suggests that RRI values decrease with recovered renal function. This indicates that RRI also might have a role later in the ICU or hospital course, but its exact role for prediction of renal recovery or progression towards CKD while the patient still is in hospital needs to be investigated in properly designed studies. In outpatients with already established CKD, RRI $\geq 0.70$ notably has shown to be predictive of both CKD progression [36, 37] and mortality [38].

Our finding of elevated RRI in COVID-19-related AKI indicates that RRI may have a role in the assessment of this new and unique disease. Further, RRI has shown potential as a precocious ICU monitoring tool for detecting progression of shock states [39, 40], and together with Doppler assessments of other splanchnic organs RRI can expand the bedside monitoring window for hypoperfusion in critically ill patients in general [41]. As a non-invasive and repeatable method that has been demonstrated to be fast to learn also for non-experienced sonographers [17, 42], RRI should be applicable within POCUS protocols for ICU clinicians and thereby contributing as a valuable tool in the present resource scarce times of a pandemic.

Our study has several limitations. First, our study population was small and although we were still able to adjust our analysis for a number of possible confounders, the results should therefore be interpreted with caution. The small number of patients with AKI stage 1 and 2 further makes it difficult to draw conclusions on the association between RRI and AKI in these specific subgroups. Second, due to the challenges of conducting clinical research during a pandemic, RRI measurements were performed at different time points in different patients and most of the measurements were made late in the ICU course. The Karolinska University Hospital is a tertiary referral hospital, and many patients were transferred to its ICUs from other hospitals when they had already received several days of intensive care. This meant there was a delay from ICU admission to accessibility in some of the patients, and we were therefore not able to perform early measurements to investigate the ability of RRI as an early predictor of subsequent AKI development. Third, intra- and inter-observer variability for the operators were not investigated. Our group has previously shown that RRI measurements by inexperienced sonographers were reliable, accurate and precise compared to an expert after only a brief training session [17], and both operators in our study were experienced with the RRI method. Lastly, our study was affected by some of the well-known pitfalls in AKI research. The use of hospital admission $\mathrm{sCr}$ as baseline level in patients in whom pre-admission $\mathrm{sCr}$ was missing might have resulted in an underestimation of the AKI incidence. Further, using $\mathrm{sCr}$ decline to define recovery from an AKI episode could in patients 
with muscle wasting during a prolonged ICU course lead to overestimation of renal function recovery [43]. However, we used eGFR calculations based on a combination of $\mathrm{sCr}$ and cystatin $\mathrm{C}$ at the time of RRI measurement and still observed a difference in estimated renal function between patients classified with or without AKI, suggesting any such misclassification was negligible.

\section{Conclusion}

Critically ill COVID-19 patients with AKI have higher RRI compared to those without AKI, and elevated RRI may have a role in identifying severe and oliguric AKI at the bedside in these patients. The exact role of RRI as a POCUS application for AKI assessment and monitoring of ICU patients with COVID-19 should be established in further studies.

\begin{abstract}
Abbreviations
COVID-19: Coronavirus disease 2019; AKI: Acute kidney injury; ICU: Intensive care unit; RRT: Renal replacement therapy; RRI: Renal resistive index; POCUS: Point-of-care ultrasonography; COVID-ICU: Intensive care unit designated for care of COVID-19 patients; SARS-CoV-2: Severe acute respiratory syndrome coronavirus 2; ESRD: End-stage renal disease; ECMO: Extracorporeal membrane oxygenation; KDIGO: Kidney Disease Improving Global Outcomes; $\mathrm{sCr}$ : Serum creatinine concentration; eGFR: Estimated glomerular filtration rate; CKD-EPI: Chronic Kidney Disease Epidemiology Collaboration; CKD: Chronic kidney disease; SOFA: Sequential Organ Failure Assessment; IQR: Interquartile range; $\mathrm{min} / \mathrm{max}$ : Minimum/maximum; OR: Odds ratio; Cl: Confidence interval; CRRT: Continuous renal replacement therapy; BMI: Body mass index.
\end{abstract}

\section{Acknowledgements}

We would like to thank all ICU health care workers that made measurements and data collection possible with their flexibility during a stressful time.

\section{Authors' contributions}

$M R, D H, M B$, and CRS conceived the study. MR, OJ and NK performed the data collection. MR and $\mathrm{DH}$ conducted the analyses and interpretation of the data. MR drafted the manuscript. DH, MB, CRS, OJ and NK substantially revised the manuscript. DH and MB supervised the process. All authors read and approved the final manuscript.

\section{Funding}

This research received no specific funding.

\section{Availability of data and materials}

The datasets used and analyzed during the current study are available from the corresponding author on reasonable request.

\section{Ethics approval and consent to participate}

The current study was approved by the Swedish Ethical Review Authority (registration number 202100-6925). The need for signed informed consent was waived. A printed information sheet was sent to each patient or next of kin with the opportunity to retrospectively withdraw participation.

\section{Consent for publication}

Not applicable.

\section{Competing interests}

The authors declare that they have no competing interests.

\section{Author details}

${ }^{1}$ Department of Perioperative Medicine and Intensive Care, Karolinska University Hospital, Solna, 17176 Stockholm, Sweden. ${ }^{2}$ Department of Physiology and Pharmacology, Karolinska Institutet, Stockholm, Sweden. ${ }^{3}$ Department of Radiology, Karolinska University Hospital, Huddinge, Stockholm, Sweden.

Received: 8 October 2020 Accepted: 19 January 2021

Published online: 05 February 2021

\section{References}

1. Yang X, Jin Y, Li R, Zhang Z, Sun R, Chen D (2020) Prevalence and impact of acute renal impairment on COVID-19: a systematic review and metaanalysis. Crit Care 24:356. https://doi.org/10.1186/s13054-020-03065-4

2. Gabarre P, Dumas G, Dupont T, Darmon M, Azoulay E, Zafrani L (2020) Acute kidney injury in critically ill patients with COVID-19. Intensive Care Med 46:1339-1348. https://doi.org/10.1007/s00134-020-06153-9

3. Hirsch JS, Ng JH, Ross DW, Sharma P, Shah HH, Barnett RL, Hazzan AD, Fishbane S, Jhaveri KD (2020) Acute kidney injury in patients hospitalized with COVID-19. Kidney Int 98:209-218. https://doi.org/10.1016/j. kint.2020.05.006

4. Hansrivijit P, Qian C, Boonpheng B, Thongprayoon C, Vallabhajosyula S, Cheungpasitporn W, Ghahramani N (2020) Incidence of acute kidney injury and its association with mortality in patients with COVID-19: a meta-analysis. J Investig Med. https://doi.org/10.1136/jim-2020-001407

5. Karagiannidis C, Mostert C, Hentschker C, Voshaar T, Malzahn J, Schillinger G, Klauber J, Janssens U, Marx G, Weber-Carstens S, Kluge S, Pfeifer M, Grabenhenrich L, Welte T, Busse R (2020) Case characteristics, resource use, and outcomes of 10021 patients with COVID-19 admitted to 920 German hospitals: an observational study. Lancet Respir Med. https://doi. org/10.1016/s2213-2600(20)30316-7

6. Cummings MJ, Baldwin MR, Abrams D, Jacobson SD, Meyer BJ, Balough EM, Aaron JG, Claassen J, Rabbani LE, Hastie J, Hochman BR, SalazarSchicchi J, Yip NH, Brodie D, O'Donnell MR (2020) Epidemiology, clinical course, and outcomes of critically ill adults with COVID-19 in New York City: a prospective cohort study. Lancet 395:1763-1770. https://doi. org/10.1016/s0140-6736(20)31189-2

7. Cheng Y, Luo R, Wang K, Zhang M, Wang Z, Dong L, Li J, Yao Y, Ge S, Xu G (2020) Kidney disease is associated with in-hospital death of patients with COVID-19. Kidney Int 97:829-838. https://doi.org/10.1016/j. kint.2020.03.005

8. Lim MA, Pranata R, Huang I, Yonas E, Soeroto AY, Supriyadi R (2020) Multiorgan failure with emphasis on acute kidney injury and severity of COVID-19: systematic review and meta-analysis. Can J Kidney Health Dis 7:2054358120938573. https://doi.org/10.1177/2054358120938573

9. Ponte B, Pruijm M, Ackermann D, Vuistiner P, Eisenberger U, Guessous I, Rousson V, Mohaupt MG, Alwan H, Ehret G, Pechere-Bertschi A, Paccaud F, Staessen JA, Vogt B, Burnier M, Martin PY, Bochud M (2014) Reference values and factors associated with renal resistive index in a family-based population study. Hypertension 63:136-142. https://doi.org/10.1161/ hypertensionaha.113.02321

10. Keogan MT, Kliewer MA, Hertzberg BS, DeLong DM, Tupler RH, Carroll BA (1996) Renal resistive indexes: variability in Doppler US measurement in a healthy population. Radiology 199:165-169. https://doi.org/10.1148/ radiology.199.1.8633141

11. Tublin ME, Bude RO, Platt JF (2003) Review. the resistive index in renal doppler sonography: where do we stand? AJR Am J Roentgenol 180:885-892. https://doi.org/10.2214/ajr.180.4.1800885

12. Haitsma Mulier JLG, Rozemeijer S, Rottgering JG, Spoelstra-de Man AME, Elbers PWG, Tuinman PR, de Waard MC, Oudemans-van Straaten HM (2018) Renal resistive index as an early predictor and discriminator of acute kidney injury in critically ill patients; a prospective observational cohort study. PLoS ONE 13:e0197967. https://doi.org/10.1371/journal.pone.0197967

13. Boddi M, Bonizzoli M, Chiostri M, Begliomini D, Molinaro A, Tadini Buoninsegni L, Gensini GF, Peris A (2016) Renal Resistive Index and mortality in critical patients with acute kidney injury. Eur J Clin Invest 46:242-251. https ://doi.org/10.1111/eci.12590

14. Song J, Wu W, He Y, Lin S, Zhu D, Zhong M (2018) Value of the combination of renal resistance index and central venous pressure in the early prediction of sepsis-induced acute kidney injury. J Crit Care 45:204-208. https://doi. org/10.1016/j.jcrc.2018.03.016

15. Lerolle N, Guerot E, Faisy C, Bornstain C, Diehl JL, Fagon JY (2006) Renal failure in septic shock: predictive value of Doppler-based renal arterial resistive 
index. Intensive Care Med 32:1553-1559. https://doi.org/10.1007/s0013 4-006-0360-x

16. Garnier F, Daubin D, Larcher R, Bargnoux AS, Platon L, Brunot V, Aarab Y, Besnard N, Dupuy AM, Jung B, Cristol JP, Klouche K (2020) Reversibility of acute kidney injury in medical icu patients: predictability performance of urinary tissue inhibitor of metalloproteinase-2 $x$ Insulin-like growth factor-binding protein 7 and renal resistive index. Crit Care Med. https://doi.org/10.1097/ ccm.0000000000004218

17. Renberg M, Kilhamn N, Lund K, Hertzberg D, Rimes-Stigare C, Bell M (2020) Feasibility of renal resistive index measurements performed by an intermediate and novice sonographer in a volunteer population. Ultrasound J 12:28. https://doi.org/10.1186/s13089-020-00175-6

18. Ostermann M, Lumlertgul N, Forni LG, Hoste E (2020) What every Intensivist should know about COVID-19 associated acute kidney injury. J Crit Care 60:91-95. https://doi.org/10.1016/j.jcrc.2020.07.023

19. Batlle D, Soler MJ, Sparks MA, Hiremath S, South AM, Welling PA, Swaminathan S (2020) Acute kidney injury in COVID-19: emerging Evidence of a distinct pathophysiology. J Am Soc Nephrol 31:1380-1383. https://doi. org/10.1681/asn.2020040419

20. Watchorn J, Huang DY, Joslin J, Bramham K, Hutchings SD (2020) Critically ILL COVID-19 patients with acute kidney injury have reduced renal blood flow and perfusion despite preserved cardiac function. Shock, A Case-Control Study Using Contrast Enhanced Ultrasound. https://doi.org/10.1097/ shk.0000000000001659

21. Kidney Disease: Improving Global Outcomes (KDIGO) Acute Kidney Injury Work Group. KDIGO Clinical Practice Guideline for Acute Kidney Injury (2012). Kidney inter, Suppl:1-138

22. Fliser D, Laville M, Covic A, Fouque D, Vanholder R, Juillard L, Van Biesen W (2012) A european renal best practice (ERBP) position statement on the Kidney Disease Improving Global Outcomes (KDIGO) clinical practice guidelines on acute kidney injury: part 1: definitions, conservative management and contrast-induced nephropathy. Nephrol Dial Transplant 27:4263-4272. https://doi.org/10.1093/ndt/gfs375

23. Brower RG, Matthay MA, Morris A, Schoenfeld D, Thompson BT, Wheeler A (2000) Ventilation with lower tidal volumes as compared with traditional tidal volumes for acute lung injury and the acute respiratory distress syndrome. N Engl J Med 342:1301-1308. https://doi.org/10.1056/nejm200005 043421801

24. Levey AS, Stevens LA, Schmid CH, Zhang YL, Castro AF 3rd, Feldman HI, Kusek JW, Eggers P, Van Lente F, Greene T, Coresh J (2009) A new equation to estimate glomerular filtration rate. Ann Intern Med 150:604-612. https://doi. org/10.7326/0003-4819-150-9-200905050-00006

25. Vincent JL, Moreno R, Takala J, Willatts S, De Mendonça A, Bruining H, Reinhart CK, Suter PM, Thijs LG (1996) The SOFA (Sepsis-related Organ Failure Assessment) score to describe organ dysfunction/failure. On behalf of the working group on sepsis-related problems of the european society of intensive care medicine. Intensive Care Med 22:707-710. https://doi.org/10.1007/ bf01709751

26. Schnell D, Deruddre S, Harrois A, Pottecher J, Cosson C, Adoui N, Benhamou D, Vicaut E, Azoulay E, Duranteau J (2012) Renal resistive index better predicts the occurrence of acute kidney injury than cystatin C. Shock 38:592-597. https://doi.org/10.1097/SHK.0b013e318271a39c

27. Darmon M, Schortgen F, Vargas F, Liazydi A, Schlemmer B, Brun-Buisson C, Brochard L (2011) Diagnostic accuracy of Doppler renal resistive index for reversibility of acute kidney injury in critically ill patients. Intensive Care Med 37:68-76. https://doi.org/10.1007/s00134-010-2050-y

28. Oliveira RAG, Mendes PV, Park M, Taniguchi LU (2019) Factors associated with renal Doppler resistive index in critically ill patients: a prospective cohort study. Ann Intensive Care 9:23. https://doi.org/10.1186/s1361 3-019-0500-4

29. Su H, Yang M, Wan C, Yi LX, Tang F, Zhu HY, Yi F, Yang HC, Fogo AB, Nie X, Zhang C (2020) Renal histopathological analysis of 26 postmortem findings of patients with COVID-19 in China. Kidney Int 98:219-227. https://doi. org/10.1016/j.kint.2020.04.003

30. Helms J, Tacquard C, Severac F, Leonard-Lorant I, Ohana M, Delabranche X, Merdji H, Clere-Jehl R, Schenck M, Fagot Gandet F, Fafi-Kremer S, Castelain
V, Schneider F, Grunebaum L, Anglés-Cano E, Sattler L, Mertes PM, Meziani F (2020) High risk of thrombosis in patients with severe SARS-CoV-2 infection: a multicenter prospective cohort study. Intensive Care Med 46:1089-1098. https://doi.org/10.1007/s00134-020-06062-x

31. Klok FA, Kruip M, van der Meer NJM, Arbous MS, Gommers D, Kant KM, Kaptein FHJ, van Paassen J, Stals MAM, Huisman MV, Endeman H (2020) Confirmation of the high cumulative incidence of thrombotic complications in critically ill ICU patients with COVID-19: An updated analysis. Thromb Res 191:148-150. https://doi.org/10.1016/j.thromres.2020.04.041

32. Bilaloglu S, Aphinyanaphongs Y, Jones S, Iturrate E, Hochman J, Berger JS (2020) Thrombosis in hospitalized patients with COVID-19 in a New York City health system. JAMA. https://doi.org/10.1001/jama.2020.13372

33. Di Nicolo P, Granata A (2019) Renal intraparenchymal resistive index: the ultrasonographic answer to many clinical questions. J Nephrol 32:527-538. https://doi.org/10.1007/s40620-018-00567-x

34. Darmon M, Bourmaud A, Reynaud M, Rouleau S, Meziani F, Boivin A, Benyamina M, Vincent F, Lautrette A, Leroy C, Cohen Y, Legrand M, Morel J, Terreaux J, Schnell D (2018) Performance of Doppler-based resistive index and semi-quantitative renal perfusion in predicting persistent AKI: results of a prospective multicenter study. Intensive Care Med 44:1904-1913. https:// doi.org/10.1007/s00134-018-5386-3

35. Wiersema R, Kaufmann T, van der Veen HN, de Haas RJ, Franssen CFM, Koeze J, van der Horst ICC, Keus F (2020) Diagnostic accuracy of arterial and venous renal Doppler assessment for acute kidney injury in critically ill patients: a prospective study. J Crit Care 59:57-62. https://doi.org/10.1016/j. jcrc.2020.05.012

36. Sugiura T, Wada A (2011) Resistive index predicts renal prognosis in chronic kidney disease: results of a 4-year follow-up. Clin Exp Nephrol 15:114-120. https://doi.org/10.1007/s10157-010-0371-3

37. Parolini C, Noce A, Staffolani E, Giarrizzo GF, Costanzi S, Splendiani G (2009) Renal resistive index and long-term outcome in chronic nephropathies. Radiology 252:888-896. https://doi.org/10.1148/radiol.2523080351

38. Toledo C, Thomas G, Schold JD, Arrigain S, Gornik HL, Nally JV, Navaneethan SD (2015) Renal resistive index and mortality in chronic kidney disease. Hypertension 66:382-388. https://doi.org/10.1161/hypertensionaha .115 .05536

39. Corradi F, Brusasco C, Vezzani A, Palermo S, Altomonte F, Moscatelli P, Pelosi $P$ (2011) Hemorrhagic shock in polytrauma patients: early detection with renal Doppler resistive index measurements. Radiology 260:112-118. https //doi.org/10.1148/radiol.11102338

40. Anile A, Ferrario S, Campanello L, Orban MA, Castiglione G (2019) Renal resistive index: a new reversible tool for the early diagnosis and evaluation of organ perfusion in critically ill patients: a case report. Ultrasound J 11:23. https://doi.org/10.1186/s13089-019-0138-3

41. Corradi F, Via G, Tavazzi G (2020) What's new in ultrasound-based assessment of organ perfusion in the critically ill: expanding the bedside clinical monitoring window for hypoperfusion in shock. Intensive Care Med 46:775-779. https://doi.org/10.1007/s00134-019-05791-y

42. Schnell D, Reynaud M, Venot M, Le Maho AL, Dinic M, Baulieu M, Ducos G, Terreaux J, Zeni F, Azoulay E, Meziani F, Duranteau J, Darmon M (2014) Resistive Index or color-Doppler semi-quantitative evaluation of renal perfusion by inexperienced physicians: results of a pilot study. Minerva Anestesiol 80:1273-1281

43. Ravn B, Rimes-Stigare C, Bell M, Hansson M, Hansson LO, Martling CR, Larsson A, Mårtensson J (2019) Creatinine versus cystatin C based glomerular filtration rate in critically ill patients. J Crit Care 52:136-140. https://doi. org/10.1016/j.jcrc.2019.04.007

\section{Publisher's Note}

Springer Nature remains neutral with regard to jurisdictional claims in published maps and institutional affiliations. 